\title{
Safety and tolerability evaluation
} after repeated intravitreal injections of a humanized anti-VEGF-A monoclonal antibody (PRO-169) versus ranibizumab in New Zealand white rabbits

\author{
Leopoldo Baiza-Durán', Alejandra Sánchez-Ríos', Joel González-Barón², Oscar Olvera-Montaño',
} Elba Correa-Gallegos ${ }^{1}$, Andrea Navarro-Sánchez ${ }^{1}$ and Patricia Muñoz-Villegas ${ }^{1 *}$ (i)

\begin{abstract}
Background: To evaluate the retinal toxicity after repeated intravitreal injections of a humanized anti-VEGF-A monoclonal antibody (PRO-169) versus ranibizumab in New Zealand white (NZW) rabbit eyes.

Methods: NZW rabbits were injected intravitreally with PRO-169 $(n=12), 1.25 \mathrm{mg} / 0.05 \mathrm{ml}$ or ranibizumab $(n=12)$, $0.5 \mathrm{mg} / 0.05 \mathrm{ml}$ into the right eye (OD), whereas the left eye (OS) of each rabbit was used as control. Three consecutive injections were administered at 30-days intervals. An electroretinogram (ERG) was recorded 30 days after each injection. Clinical examination was conducted before and after injections, including intraocular pressure determination and eye fundus exploration. Eyes were enucleated and retina, cornea, conjunctiva, ciliary body and optic nerve were prepared for histopathology assessment.

Results: ERG of the experimental and control eyes in PRO-169 and ranibizumab groups were similar in amplitude and pattern throughout the follow-up period. Clinical examination found no alterations of intraocular pressure (IOP). No retinal damage was observed in both, the experimental and control eyes, of all the rabbits. The histopathologic studies showed similar results in both groups, showing no signs of structural damage.
\end{abstract}

Conclusions: Our study did not find evidence of retinal toxicity from a repeated intravitreal injection of PRO-169 or ranibizumab (Lucentis ${ }^{\circledR}$ ) in NZW rabbits. These findings support intravitreal PRO-169 as a safe candidate to develop as a future alternative for the treatment of retinal neovascularization diseases.

Keywords: Anti-vascular endothelial growth factor, Electroretinogram, Naka-Rushton function, Retina neovascularization

*Correspondence: patricia.munoz@sophia.com.mx

${ }^{1}$ Medical Affairs; Laboratorios Sophia, SA de CV, Paseo del Norte 5255, Guadalajara Technology Park, Zapopan, Jalisco, Mexico

Full list of author information is available at the end of the article

\begin{abstract}
Background
Vascular endothelial growth factor (VEGF) promotes angiogenesis and neovascularization, regulating vascular differentiation and permeability [1]. Its presence is necessary in order to maintain the normal functions of the eye, yet it can be harmful when it is overproduced, as it happens in diseases whose pathophysiology is based on
\end{abstract}

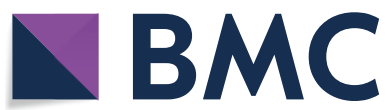

(c) The Author(s) 2020. This article is licensed under a Creative Commons Attribution 4.0 International License, which permits use, sharing, adaptation, distribution and reproduction in any medium or format, as long as you give appropriate credit to the original author(s) and the source, provide a link to the Creative Commons licence, and indicate if changes were made. The images or other third party material in this article are included in the article's Creative Commons licence, unless indicated otherwise in a credit line to the material. If material is not included in the article's Creative Commons licence and your intended use is not permitted by statutory regulation or exceeds the permitted use, you will need to obtain permission directly from the copyright holder. To view a copy of this licence, visit http://creativeco mmons.org/licenses/by/4.0/. The Creative Commons Public Domain Dedication waiver (http://creativecommons.org/publicdomain/ zero/1.0/) applies to the data made available in this article, unless otherwise stated in a credit line to the data. 
neovascularization of the retina. Diabetic retinopathy (DR), age-related macular degeneration (ARMD), retinopathy of prematurity (ROP) and central retinal vein occlusion (CRVO) are some of such diseases; and their prevalence is a real public health threat [2-4]. DR alone affects up to $80 \%$ of patients with chronic Diabetes Mellitus, while diabetic macular edema is diagnosed in $16 \%$ of them [5, 6].

To inhibit VEGF, many anti-VEGF agents have been developed, and their use has increased dramatically over the last decade. Bevacizumab is a humanized monoclonal antibody (mAb) approved by the Food and Drug Administration (FDA) for metastatic colorectal cancer, which has also been used extensively as an off-label intravitreal treatment for many neovascular related retinal conditions. PRO-169 is a recombinant, humanized anti-VEGFA mAb with a molecular mass of $149 \mathrm{kDa}$, structurally similar and with a target specificity like bevacizumab (Avastin, Genentech, South San Francisco, CA) [7, 8]. The peptide map of PRO-169 is consistent with bevacizumab's which confirms its identity, and the structure is typical of an $\mathrm{IgG}_{1}$ antibody predominantly comprised of parallel $\beta$-sheets. The vitreous pharmacokinetics of a single intravitreal injection of PRO-169 have been evaluated by surface plasmon resonance (SPR) in a preclinical study in NZW rabbits. PRO-169 has a similar pharmacokinetic profile to commercially available bevacizumab, see Table 1. Ranibizumab (Lucentis, Genentech) is a fab fragment from bevacizumab's mAb. The major differences between bevacizumab and ranibizumab are their molecular weights (149 vs $48 \mathrm{kDa}$, respectively) and the number of VEGF binding sites ( 2 vs 1 ) on each. Both drugs have demonstrated equivalent clinical effects as ARMD treatment throughout the first year of follow-up $[9,10]$. Bevacizumab's effectiveness and safety profile has been confirmed through many preclinical studies, including in vivo studies in numerous species. Many of these have shown that the repeated intravitreal injections of bevacizumab or ranibizumab have no long-term deleterious effects on the electrophysiological and morphologic integrity of the retina [1, 11-17]. Another preclinical in vivo study reported that after Choroidal Neovascularization $(\mathrm{CNV})$ induction through retinal photocoagulation, PRO-169 administration (1.25 mg per eye) can inhibit the retinal thickness and fluorescein leakage area without toxic effect or adverse events in a rhesus monkey model [4]. Assessing retinal toxicity of PRO-169, through controlled research in an animal model using ERG and clinical tests after repeated intravitreal (Ivt) injections was needed. Long-term VEGF suppression may produce a toxic effect on the retina. Repeated monthly Ivt injections of bevacizumab or ranibizumab over a three-month period have no cumulative toxic effect on the retina in rabbits as judged by the electroretinogram (ERG) $[1,13]$.

The purpose of this in vivo preclinical study was to assess the retinal toxicity after repeated intravitreal injections of a humanized anti-VEGF-A monoclonal antibody (PRO-169) versus ranibizumab (positive control) in New Zealand White (NZW) rabbit eyes.

\section{Methods \\ Animals}

A total of 24 experimental animals were included in this study. Inclusion criteria were: healthy male NZW rabbits aged 2 to 3 months and weighing between 2 and $3 \mathrm{~kg}$, with no history of participation in any previous study. All subjects were submitted to at least 7 days of quarantine, in which general health was assessed, and, weight, food and water uptake were registered. An ophthalmic eligibility screening with slit lamp examination and fluorescein

Table 1 Characterization of PRO-169

\begin{tabular}{|c|c|c|}
\hline Test & Method & PRO-169 \\
\hline \multirow[t]{2}{*}{ Quality } & Appearance & Slightly yellow, opalescent liquid \\
\hline & $\mathrm{pH}$ & 6.2 \\
\hline Charge of heterogeneity & CEX-HPLC & $55.1 \%$ main peak, 34.3\% acidic variants, and 10.7 basic variants \\
\hline \multirow[t]{2}{*}{ Structure } & Intact mass LC/MS, GOF/GOF & $149201 \mathrm{Da}$ \\
\hline & Deglycosylated partially reduced LC/MS & $\begin{array}{l}\text { Light chain mass }=23450.8 \mathrm{Da} \text {, deglycosylated heavy chain } \\
\text { mass }=49717.5 \mathrm{Da}\end{array}$ \\
\hline Oligosaccharide profile & N-Glycan profiling & $79.2 \%$ G0, $16.1 \%$ G1, and $0.9 \%$ G2 \\
\hline Other & SPR & $K_{D}=6.54 \times 10^{-6}$ \\
\hline \multirow[t]{3}{*}{ Vitreous Pharmacokinetics } & SPR & $C_{\operatorname{Max}} \pm S D=593.7 \pm 42.6 \mu \mathrm{g} / \mathrm{ml}$ \\
\hline & & $\mathrm{T}_{\text {Max }} \pm \mathrm{SD}=0.53 \pm 0.8$ days \\
\hline & & $\mathrm{T}_{1 / 2} \pm \mathrm{SD}=4.99 \pm 0.9$ days \\
\hline
\end{tabular}


staining was performed to ensure there were no exclusion criteria present, such as: secretion, conjunctival hyperemia, corneal or conjunctival lacerations, de-epithelization or scarring, corneal degeneration or neovascularization, cataract, reduction in aqueous humor transparency, or any pathological findings in the indirect fundoscopy performed with a $78 \mathrm{D}$ lens, including retinal detachment, tears or neovascularization. Finally, the elimination criteria included any serious adverse event that required the administration of a complementary ophthalmic or systemic treatment, including any situation that entailed any compromise to the animal's well-being. All animal studies were conducted according to the ARVO Statement for the Use of Animals in Ophthalmic and Vision Research; they were approved by Institutional Animal Care and Use Committee of Laboratorios Sophia, SA de CV (CICUALLS). The NZW rabbits were housed under a 12/12-h light/dark cycle with free access to food and water. Slitlamp and indirect funduscopic examinations were performed on all eyes before the study began, and on days $2,3,4,8,15,22,29,33,34,35,39,46,53,60,64,65,66$, $70,77,84$ and 91 ; and Ivt injections took place on days 1, 32 and 63 ( $n=4$ NZW rabbits per group), see Fig. 1. One rabbit (PRO-169 group) died during the follow-up period (after the $3^{\text {rd }}$ Ivt injection, day 92), and therefore only data from 23 rabbits was used for the histologic examination.

\section{Anesthesia procedure}

Before Ivt injection and electrophysiological testing, the animals were anesthetized with an intramuscular injection of $10 \mathrm{mg} / \mathrm{kg}$ body weight of xylazine $\left(\mathrm{PROCIN}^{\circledR}\right.$ Pisa, Hidalgo, Mexico), and $30 \mathrm{mg} / \mathrm{kg}$ of ketamine hydrochloride (ANESKET ${ }^{\circledR}$ VET, Pisa, Hidalgo, Mexico). Topical anesthesia (tetracaine hydrochloride $0.5 \%$, Ponti ${ }^{\circledR}$ Ofteno, Laboratorios Sophia, Zapopan, Jalisco, Mexico) was administered to prevent any potential discomfort.

\section{Intravitreal injection}

Before Ivt injection, animals were subjected to an asepsis and antisepsis protocol for eyelid and eyelash with an iodate solution (50\%) (Isodine ${ }^{\circledR}$, Boehringer Ingelheim, Germany) plus a drop of iodate solution (5\%) placed in the conjunctival sac. Test article, PRO-169 is a mAb AntiVEGF (Laboratorios Sophia, SA de CV, Zapopan, Jalisco, Mexico by KBI Biopharma). Positive control, ranibizumab (Lucentis ${ }^{\circledR}$, Novartis Pharmaceuticals, Genentech Inc, San Francisco, CA, USA) is a commercially available monoclonal antibody; Ivt injections were performed under sterile conditions. A 30-gauge needle attached to a syringe containing test or control article (PRO-169 $1.25 \mathrm{mg} / 0.05 \mathrm{ml}$ or ranibizumab $0.5 \mathrm{mg} / 0.05 \mathrm{ml}$ into the right eye) was used for Ivt injection through an area $1.5-2 \mathrm{~mm}$ posterior to the limbus, inside the vitreous cavity in the superonasal quadrant. The eye was held by 0.12 forceps during the procedure. Injection was done slowly with the bevel of the needle pointing away from the retina to avoid any undesired mechanical damage. At the end of the procedure, a broad-spectrum antibiotic eye drop was applied four times per day for seven days (ciprofloxacin $0.3 \%$, Sophixin ${ }^{\circledR}$ Ofteno, Laboratorios Sophia, SA de CV, Zapopan, Jalisco, Mexico).

\section{Electroretinogram (ERG)}

Electroretinography using the UTAS-3000 system (LKC Technologies, Gaithersburg, MD) was performed 30 days after each injection. The ERG responses were recorded simultaneously from the experimental (OD) and control (OS) eyes. The rabbits were dark adapted for at least $30 \mathrm{~min}$ after pupillary dilation $(\sim 8 \mathrm{~mm})$. ERG-jet electrodes (Universe SA, Switzerland) were placed on both corneas after applying methylcellulose 2\% (Meticel $^{\circledR}$ Ofteno, Laboratorios Sophia, SA de CV, Zapopan, Mexico), the negative electrode was placed on a shaved forehead's section, and a ground electrode was clipped on

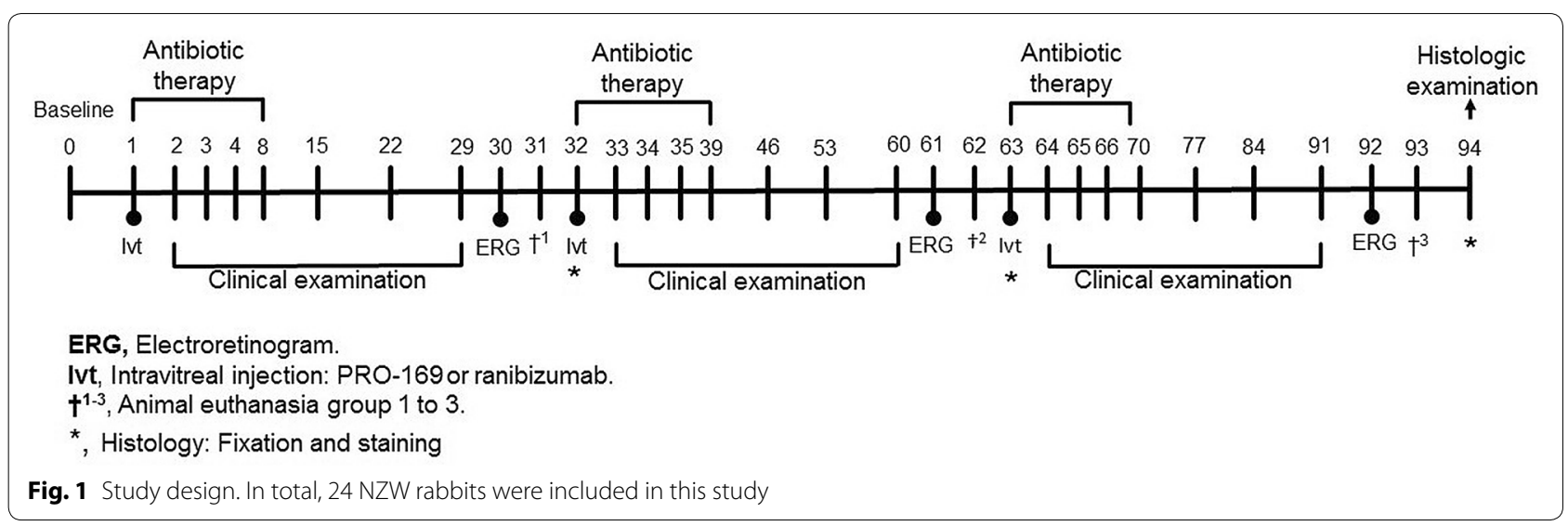


the subject's ear (Grass ${ }^{\circledR}$ electrodes, USA). Light signals were obtained from a Ganzfeld optoelectronic stimulator (Universial, Metrovision) [10]. A homologated procedure was performed with different flash intensities $(-35$, $-30,-25,-20,-15,-10,-3,0$ and $3 \mathrm{~dB}$ ), ERGs were recorded with a standard white flash without attenuation and a scotopic background. Three to ten responses elicited by identical flashes applied at 4-30-s intervals were averaged in the dark-adapted state. Each ERG was performed by a doctor who was blinded to the treatment groups to minimize the observer bias. ERG analysis was based on amplitude measurements of the b-waves. Dark adapted rod and mixed ERG responses were obtained in order to assess the linear scotopic rod function, however, some interaction from the cone function was expected since it is impossible to avoid it completely. Amplitudes were measured from baseline to cornea-positive peak. For each rabbit, the amplitudes of the experimental and control eyes were plotted as a function of log light energy. The response-stimulus energy relationship was fitted to a Naka Rushton-type hyperbolic function $[1,11,12,18]$.

$$
V / V_{\mathrm{Max}}=I(I+\sigma)
$$

where $\mathrm{V}$ is the amplitude of the b-wave elicited by a stimulus of energy $\mathrm{I}\left(\mathrm{cd} \mathrm{s} / \mathrm{m}^{2}\right), \mathrm{V}_{\mathrm{Max}}$ is the maximum response asymptotic amplitude of the b-wave $(\mu \mathrm{V})$, and $\sigma$ is the semisaturation constant. For each stimulus intensity response, the mean $\mathrm{V} / \mathrm{V}_{\mathrm{Max}}$ was calculated for the injected eyes and compared with the $\mathrm{V} / \mathrm{V}_{\mathrm{Max}}$ for the control eyes (not injected). The amplitude ratio (experimental/control) served as an index of PRO-169 and ranibizumab effect on photopic retinal function. To assess retinal response, the data obtained at each ERG recording session was derived to the entire responsestimulus energy relationship and the $V_{\text {Max }}$ ratio (experimental/control eye) and the semi saturation constant difference (experimental-control) of the dark-adapted b-waves were calculated [19]. Previous studies have reported that with this approach, technical factors such as depth of anesthesia and duration of adaptation did not affect the evaluation of retinal function $[12,13,20]$.

\section{Clinical observation}

Evaluations were performed 7 times after each Ivt injection. The posterior segment was evaluated by slit lamp (Luxvision ${ }^{\circledR}$, Class I Type B, Doral FL, USA), and an exploration $78 \mathrm{D}$ lens (Ocular Instruments, Belleveu, WA, USA). The structures involved during this evaluation were; vitreous, retina, macula, fovea, choroid, optic nerve, and blood vessels. Without changing the slit-lamp settings, the anterior chamber was examined for the presence of cells $(0.5+$ at $4.0+)$. The intraocular pressure (IOP) was measured with Goldmann tonometer (Luxvision $^{\circledR}$, YZ30, Doral FL, USA).

\section{Histopathologic evaluation}

The animals were euthanatized after the ERG (on the 31th $[n=8], 62 n d[n=8]$ and 93th day $[n=7]$ ) by intravenous injection of $100 \mathrm{mg} / \mathrm{Kg}$ body weight of pentobarbital (Doléthal ${ }^{\circledR}$, Vétoquinol, SA, Distrito Federal, Mexico). An ophthalmologist performed a bilateral enucleation of all twenty-three NZW rabbits [21]. The enucleated eye was fixed for $24-48 \mathrm{~h}$ in a solution of $4 \%$ paraformaldehyde. Paraffin sections of $4 \mu \mathrm{m}$ were prepared, stained with hematoxylin, eosin and AAPas for examination with light microscope. The goblet cells were counted using high power field $(\times 40)$.

\section{Statistical analyses}

Statistical analyses were carried out using SPSS 19.0 software for Windows (SPSS Inc., Chicago, IL, USA). Microsoft ${ }^{\circledR}$ Office Excel 2016 was used for data processing. MATLAB ${ }^{\circledR}$ 2019a software for Mac (MathWorks Inc ${ }^{\circledR}$, Natick, Massachusetts, USA) was used for data analyses on ERGs. Statistical significance was determined by Mann-Whitney test for continuous data, and Chi square test or Fisher's exact test for categorical data. All statistical analyses performed in this study were with $p$ values $\leq 0.05$ considered statistically significant.

\section{Results}

\section{Electroretinogram}

Dark-adapted ERG responses from the experimental (OD) and control (OS) eyes were similar in pattern and amplitude through the follow-up period. During the recording sessions, different flash intensities were used to derive the response-log stimulus strength relationship. Similar results were noted for animals treated with repeated injections of PRO-169 or ranibizumab, as represented by ERG response-stimulus energy relationship $\left(\mathrm{V} / \mathrm{V}_{\mathrm{Max}} / \log \sigma\right)$, as shown in Fig. 2. ERG changes were considered significant if the follow-up differences in amplitude (b-waves) were over $20 \%$ inferior in the test article (PRO-169) group when compared to the positive control (ranibizumab). Both groups only showed a decrease in amplitude at day 60 (after 2 Ivt injection) of $32.3 \%$ for PRO- 169 and $12.7 \%$ in ranibizumab when compared to day $30(\mathrm{p}=0.386)$. This study did not show a significant decrease in amplitude in both groups at day 90 when compared to day $60(\mathrm{p}=0.386)$, and at day 90 when compared to the day $30(\mathrm{p}=0.564)$. No significant differences in retinal response were found between the PRO169 and ranibizumab groups at any time point, expressed in $\mathrm{V}_{\mathrm{Max}}$ (p-values: $0.248,1.000,0.248$ on day 30,60 and 90 , respectively) and $\sigma$ values (p-values: $0.486,0.858$ and 

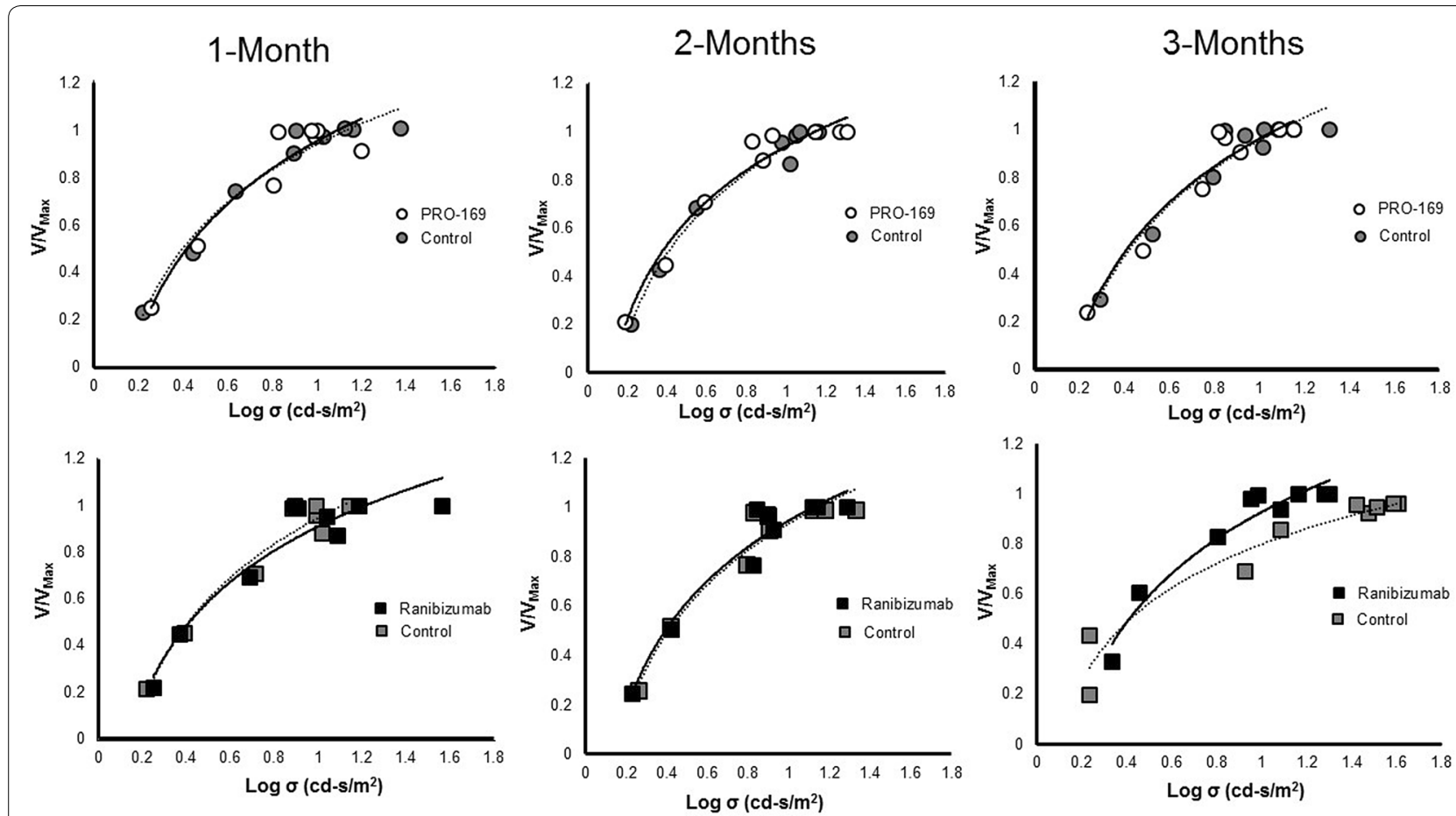

Fig. 2 Response-stimulus strength for the dark-adapted ERG b-wave for each ERG recording session (1, 2 and 3-months), from experimental (OD) and the control (OS) eyes. The relationships were fitted to hyperbolic function (Eq. 1) to derive the maximal amplitude response $\left(V / N_{\text {Max }}\right)$ and the semi saturation constant ( $\sigma$ ). For PRO-169 and ranibizumab at each recording session, the response-stimulus energy relationship of the control and experimental eyes are similar

0.384 on day 30, 60 and 90). The effects of the PRO-169 and ranibizumab on the dark-adapted retinal responses are represented in Table 2 and showed in Fig. 3a. The mean \pm standard deviation (SD) for the $\mathrm{V}_{\text {Max }}$ ratio of the ERG b-wave for the PRO-169 group were $0.879 \pm 0.755$, $1.031 \pm 0.148$ and $1.050 \pm 0.378$ at 30,60 and 90 days respectively; meanwhile for the ranibizumab group they were $1.007 \pm 0.328, \quad 0.907 \pm 0.123$ and $1.118 \pm 0.347$ (p-values: $0.248,0.248$ and 1.000, respectively). No electroretinographic deficit was found for the two treatments across the follow-up period, the dark-adapted b-wave $\mathrm{V}_{\mathrm{Max}}$ ratio of the maximal amplitudes was close to unity and the difference in the log semi saturation constant of the dark-adapted ERG b-wave was small and close to zero in 30, 60 and 90 days after the Ivt injection. See Fig. 3b.

Table 2 ERG's Maximum b-wave amplitude and semi saturation constant from the rabbits treated with PRO-169 and Ranibizumab intravitreal injections

\begin{tabular}{|c|c|c|c|c|c|c|}
\hline & \multicolumn{2}{|c|}{ Experimental eye } & \multicolumn{2}{|c|}{ Control eye } & \multirow[t]{2}{*}{$\mathrm{V}_{\max }$ ratio } & \multirow[t]{2}{*}{$\delta \log \sigma$} \\
\hline & $\mathrm{V}_{\max }(\mu \mathrm{V})$ & $\log \sigma\left(c d s / m^{2}\right)$ & $\mathrm{V}_{\max }(\mu \mathrm{V})$ & $\log \sigma\left(c d s / m^{2}\right)$ & & \\
\hline \multicolumn{7}{|l|}{ PRO-169 } \\
\hline 1 month & 128.747 & -2.626 & 154.359 & -2.253 & 0.879 & -0.373 \\
\hline 2 months & 276.490 & -2.313 & 266.438 & -2.353 & 1.031 & 0.040 \\
\hline 3 months & 286.428 & -2.473 & 238.032 & -2.756 & 1.050 & 0.094 \\
\hline \multicolumn{7}{|l|}{ Ranibizumab } \\
\hline 1 month & 135.376 & -2.177 & 136.858 & -2.218 & 1.007 & 0.041 \\
\hline 2 months & 268.382 & -2.468 & 299.659 & -2.332 & 0.907 & -0.136 \\
\hline 3 months & 241.647 & -2.696 & 229.543 & -2.760 & 1.118 & 0.064 \\
\hline
\end{tabular}

Medium values. No significant differences between experimental (OD) and control eyes (OS) and between groups (injected eyes), in all comparisons, $p>0.05$ (MannWhitney $\mathrm{U}$ test), $\mathrm{n}=4 \mathrm{NWZ}$ rabbit's eyes per group 


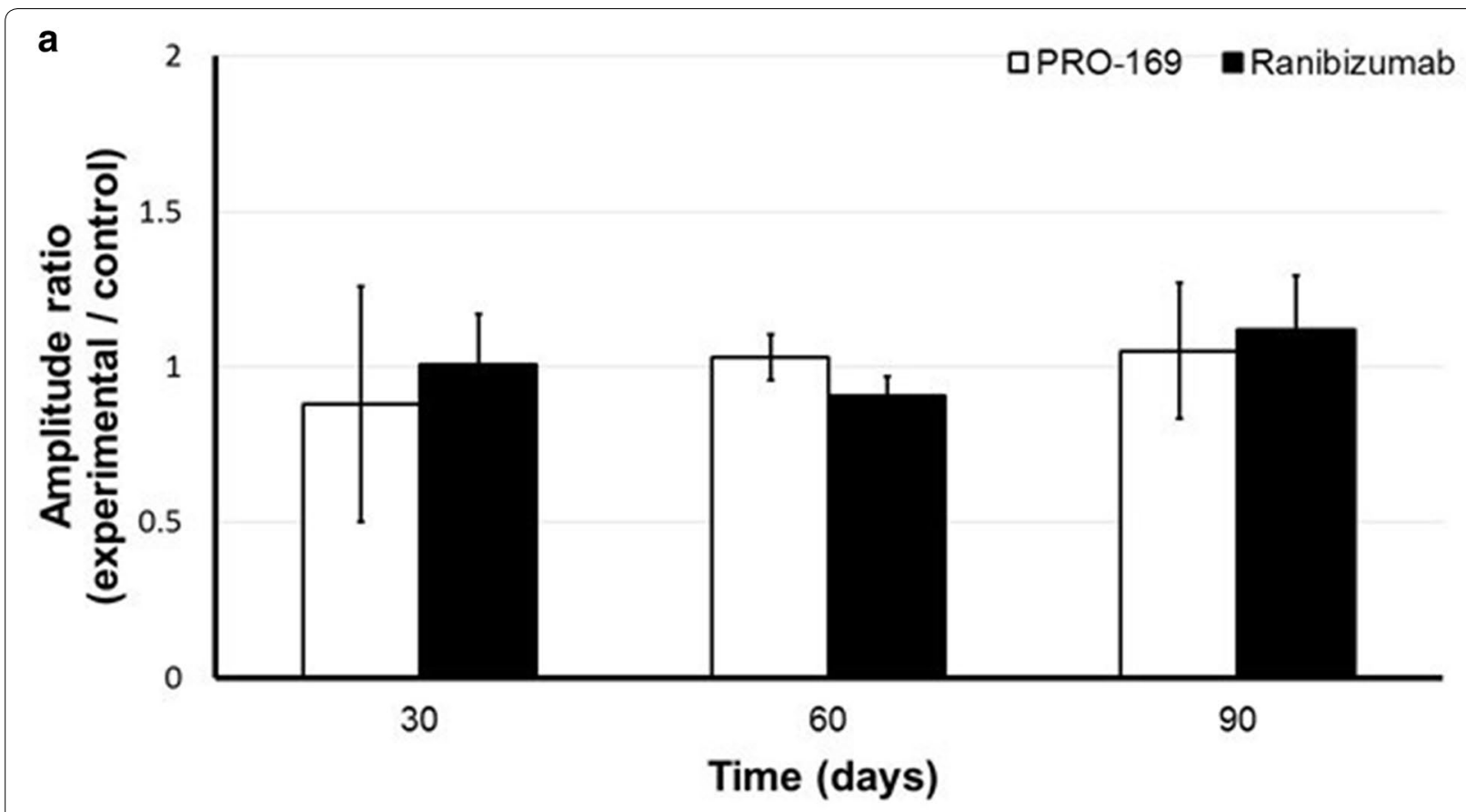

b

PRO-169

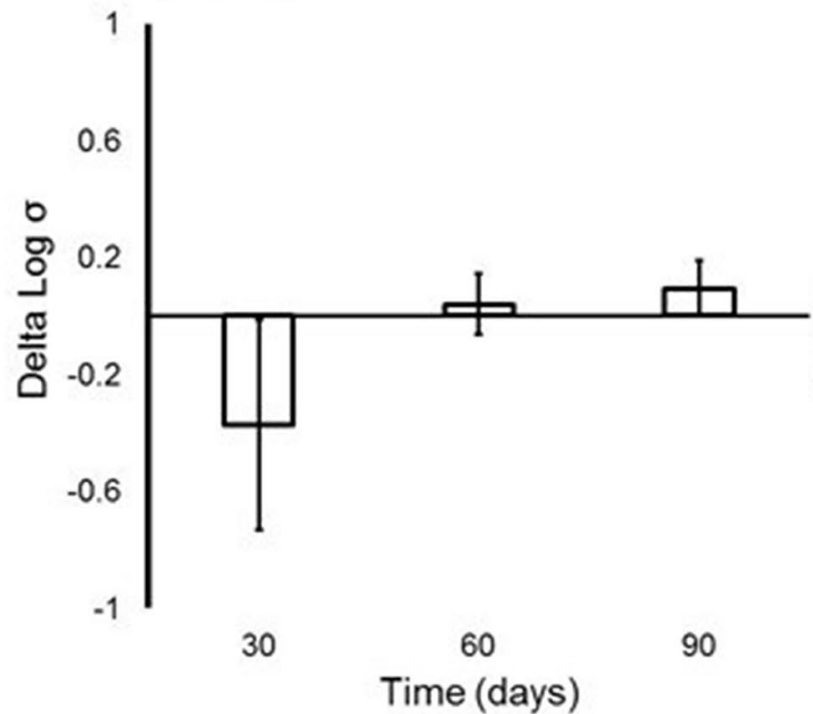

\section{Ranibizumab}

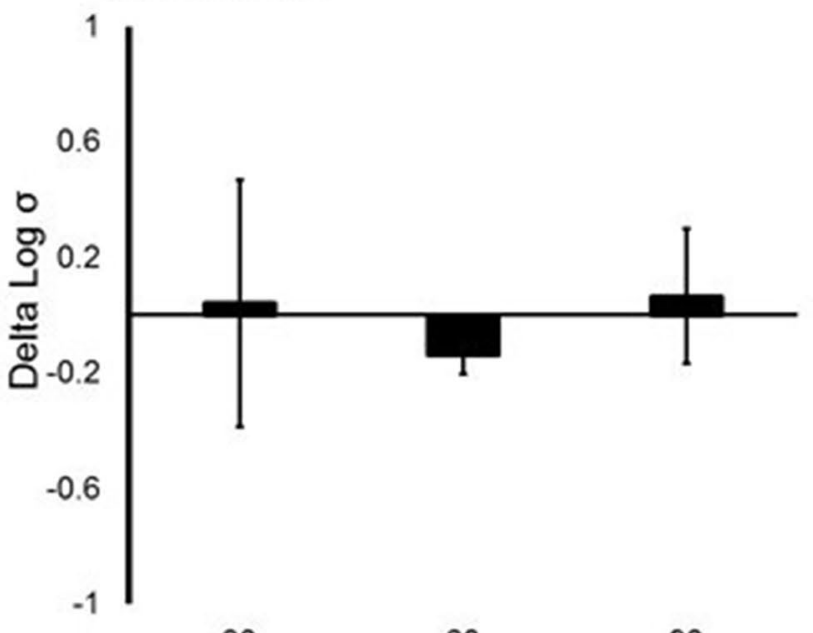

30
60

Time (days)

Fig. 3 ERG analysis of NZW rabbits as a function of time after intravitreal injections. a The effects of the intravitreal PRO-169 (white bars) and ranibizumab (dark bars) on the dark-adapted ERG responses after 30 days of each injection. The dark-adapted retinal response is represented by the mean $\pm S E M V_{\text {Max }}$ ratio of the ERG (b-wave). $\mathbf{b}$ Time dependent effects of repeated injections of PRO-169 and ranibizumab on retinal function of rabbits. The difference of the log semi saturation constant (experimental-control) is represented by the mean \pm SEM. $V_{\text {Max }}$ ratios are around 1 and log $\sigma$ differences are around 0 , indicating no damage to the road system

\section{Clinical observation}

$100 \%$ of the eyes examined in both treatments presented absence of any pathological condition, active or inactive in retina, macula, fovea, choroid, optic nerve and, blood vessels. Evidence of eye inflammation was seen in the anterior segment of ranibizumab injected rabbit eyes 
after the 3rd Ivt (64 at 77 day), no significant differences were observed $(p=1.000)$. Ophthalmic examination revealed an appearance of the cells in the anterior chamber (mild to moderate) in 2 of 8 eyes which received PRO-169 and 2 of 8 eyes which received ranibizumab. There was no significant difference in the cellularity described in the anterior chamber between both groups. Additionally, one eye in the PRO-169 group (46 at 60 day) and one eye in ranibizumab group (D29) presented posterior vitreous detachment.

Ocular tonometry showed no significant differences in the IOP between PRO-169 and ranibizumab groups after $30(8.75 \pm 0.4$ vs $8.92 \pm 0.5 \mathrm{mmHg} ; \mathrm{p}=0.422), 60$ $(8.63 \pm 0.5$ vs $8.75 \pm 0.5 \mathrm{mmHg} ; \mathrm{p}=0.602)$ or 90 days $(8.50 \pm 0.6$ vs $8.75 \pm 0.5 \mathrm{mmHg} ; \mathrm{p}=0.495)$.

Finally, no subjects presented cataract formation after intravitreal application of either product. The incidence of adverse events was similar between groups.

\section{Histopathologic evaluation}

Light microscopy was performed in all eyes (experimental and control). No retinal toxicity was found in any eyes. The histology of both groups of treated eyes (PRO-169 and ranibizumab) after Ivt injections did not show anatomic signs of toxicity or structural damage, see Fig. 4a-f. In addition, no significant differences were observed in the number of goblet cells (AAPas \%) between treatments, after 30 and 90 days $(\mathrm{p}=0.762, \mathrm{p}=0.856)$. After 60 days, the number of goblet cells on the PRO-169 group was statistically lower when compared to ranibizumab $(\mathrm{p}=0.037)$.

\section{Discussion}

There is a large number of patients who suffer angiogenesis related diseases such as DR, which affects up to $80 \%$ of patients with chronic Diabetes Mellitus, and diabetic macular edema. Anti-VEGFs are among the treatment options for such patients $[3,8]$. These agents inhibit VEGF, an important angiogenesis and neovascularization regulator. VEGF is found in conditions such as ARMD, $\mathrm{DR}, \mathrm{ROP}$, etc. Bevacizumab is a humanized mAb widely injected intravitreally to treat these diseases, even if this administration route and indication is currently considered off-label. Many studies have been executed to confirm Bevacizumab's safety, including preclinical in vivo studies (NZW rabbits, mice, rats, Dutch rabbits, Cynomolgus monkeys, etc.) $[1,11-16,20]$. The main variable in these is usually the retinal response as studied by ERG and anatomical integrity evaluated through histopathological evaluation. Studies of the ERG pattern of rabbits have proven that the use of interindividual control eyes for testing toxicity is more sensitive, where variability

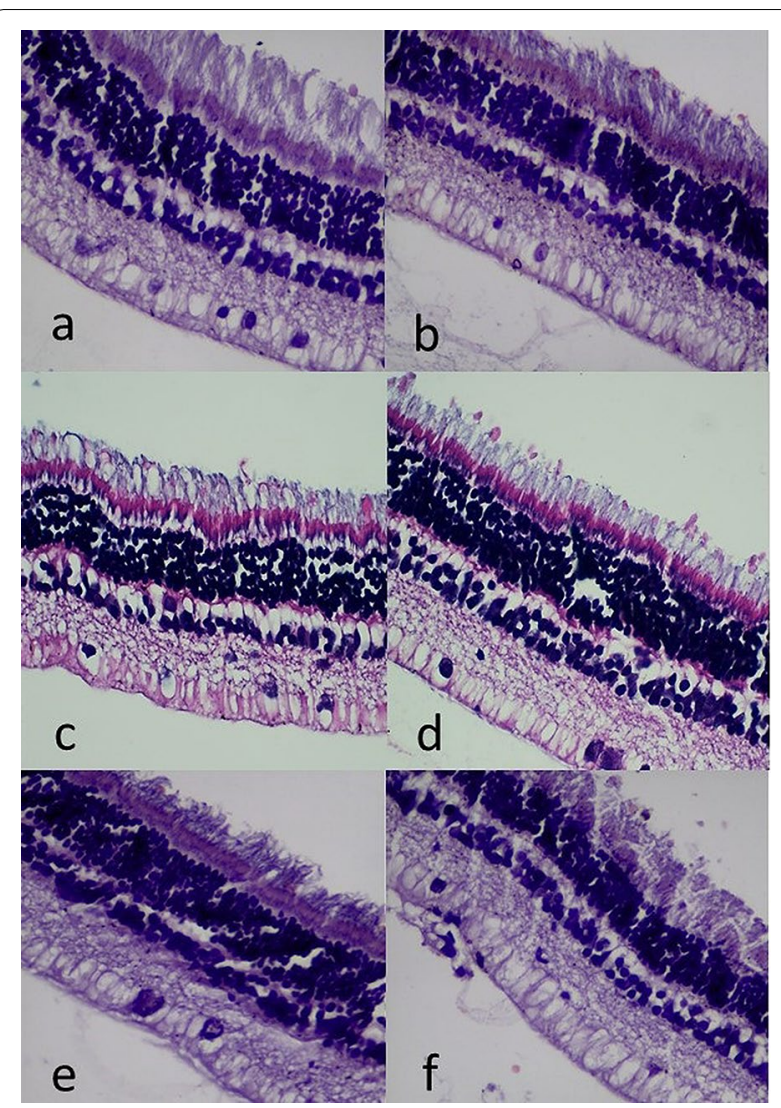

Fig. 4 Histologic examination of the central retina for PRO-169 (a) vs ranibizumab (b) after the 1st Ivt injection (D32), for PRO-169 (c) vs ranibizumab (d) after the 2nd Ivt injection (D63), and for PRO-169 (e) vs ranibizumab (f) after the 3rd Ivt injection (D94). No retinal toxicity was found in any eyes $(x 40)$

(relative $95 \%$ limits of agreement) is $10 \%$ as opposed to $33 \%$ between individuals, and 20\% across sessions [22].

PRO-169, is a mAb structurally like bevacizumab on target specificity, identity and pharmacokinetics, specific for ophthalmic use. On a laser-induced CNV rhesus monkey model, it demonstrated to be able to reduce the retinal thickness and fluorescein leakage area after treatment for 2 and 4 weeks, without toxic effect or adverse events [4]. However, controlled research in an animal model using electrophysiological and clinical tests after repeated intravitreal injections was needed. This research was designed to assess retinal toxicity of PRO-169 versus ranibizumab (positive control), administered as repeated Ivt injections in a NZW rabbit model.

The main outcome ERG variable considered in this study was $\mathrm{V}_{\mathrm{Max}}$, assessing the integrity of the photoreceptors through the saturation of the $\mathrm{b}$-wave. The $\mathrm{V} / \mathrm{V}_{\mathrm{Max}}$ relationship was also studied to evaluate the integrity of the overall retina's sensibility. The Naka-Rushton equation describes the empirical amplitude of the adapted 
wave (b-wave) as a function of the luminance stimulus. This equation was adapted accordingly to fit the ERG's parameters $[1,11,13]$. Both $\mathrm{V}_{\mathrm{Max}}$ and $\sigma$ values, evaluating amplitude and sensitivity respectively, showed no significant differences when comparing both treatments ( $\left.p^{3} 0.05\right)$. The only difference between both groups appeared as a decrease of $32.3 \%$ in amplitude at day 60 for PRO-169, and $12.7 \%$ for ranibizumab when compared to day $30(\mathrm{p}=0.386)$. There was no evidence of a significant decrease in amplitude in both groups at day 90 when compared to day $60(\mathrm{p}=0.386)$, and at day 90 when compared to the day $30(\mathrm{p}=0.564)$.

The clinical observation included a complete slit lamp evaluation of the anterior segment and IOP, as well as a fundus evaluation during a total of 7 visits after each intravitreal injection. The outcome variable for safety was the presence of cellularity in the anterior chamber as a sign of inflammation. This cellularity was described (mild to moderate) in 2 of 8 eyes after receiving PRO-169 and 2 of 8 eyes in the ranibizumab group. There was no significant difference in the amount of cells described in the anterior chamber between both groups. Due to the nature of the administration method, these findings were attributed to inflammation secondary to the intravitreal injection itself, since this is an invasive procedure and such events have been described before for this route of administration [23, 24]. Additionally, the deceased subject on day 92 belonged to the PRO-169 three-applications group. It did not present any clinical finding that suggested illness prior to its death, the necropsy indicated that was non-related to treatment.

Finally, histopathological evaluation of the enucleated eyes was performed. After fixation and staining with hematoxylin, eosin and AAPas there was no evidence of toxicity or any significant difference in the findings between subjects of both groups. Other authors [12, 16, 25], have evaluated the toxicity in NZW rabbits' enucleated eyes after exposure to bevacizumab and other anti-VEGF molecules through histologic analysis including hematoxylin and eosin (H\&E) staining. Comparably to our study, no significant difference in retinal toxicity were reported between experimental and control groups. And the incidence of adverse events was similar between PRO-169 and ranibizumab groups.

The limitations of this study were the model used, the scarce number of subjects in each group per product and number of intravitreal injections administered. The albino condition of the species used does modify the retinal response in the ERG due to scatter and reflection at the retinal layer $[19,20]$. However, the fact that this was a comparative evaluation between PRO-169 and ranibizumab in the same animal model parallels the results and attests to the value of the correlation of the studied parameters. It is also worth mentioning that NZW rabbits have been used amply to assess the safety of this kind of medication intravitreally administered medications by other authors, providing valuable information comparable to that shown on this study. On regards of the small number of subjects used, a resource equation method was used to calculate the sample size with the purpose of avoiding to use a number of animals greater than the strictly necessary to obtain reliable data [26, 27]; especially for the study of pharmaceuticals with an acknowledged broad safety profile such as these.

\section{Conclusion}

In conclusion, all the variables studied in this preclinical study, including ERG responses, clinical evaluation and histopathological findings confirm that the safety profile of the anti-VEGF PRO-169 is comparable to that of ranibizumab, the currently commercially available molecule approved for intravitreal injection as treatment for patients with neovascular conditions affecting their retina.

\section{Abbreviations}

ARMD: Age-related macular degeneration; CNV: Choroidal neovascularization; DR: Diabetic retinopathy; CRVO: Central retinal vein occlusion; ERG: Electroretinogram; IOP: Intraocular pressure; Ivt: Intravitreal; mAb: Monoclonal antibody; NZW: New Zealand white; OD: Right eye; OS: Left eye; OP: Retinopathy of prematurity; VEGF: Vascular endothelial growth factor.

\section{Acknowledgements}

We thank, Manuel Medina for his technical assistance during the experiment.

\section{Authors' contributions}

All authors contributed significantly to this study, study conceptualization, to data analysis, drafting or revising the article, gave final approval of the version to be published, and agree to be accountable for all aspects of the work. All authors read and approved the final manuscript.

\section{Funding}

This study was sponsored by Laboratorios Sophia, SA de CV (Zapopan, Jalisco, Mexico). The sponsor provided support in the form of salaries for authors (BDL, SRA, MVP, OMO, CGE and NSA), this does not alter our adherence to the Good Publication Practice guidelines for pharmaceutical companies (GPP3) polices on sharing data and materials.

\section{Availability of data and materials}

The datasets generated and analyzed during the current study are available in Open Science Framework (https://osf.io) at https://doi.org/10.17605/osf.io/ n8thw.

Ethics approval and consent to participate

Not applicable.

\section{Consent for publication}

Not applicable.

Competing interests

The authors declare that they have no other competing interest in this work. 


\section{Author details}

${ }^{1}$ Medical Affairs; Laboratorios Sophia, SA de CV, Paseo del Norte 5255, Guadalajara Technology Park, Zapopan, Jalisco, Mexico. ${ }^{2}$ Clínica Lacandones, Guadalajara, Jalisco, Mexico.

Received: 27 November 2019 Accepted: 22 July 2020

Published online: 28 July 2020

\section{References}

1. Zayit-Soudry S, Zemel E, Loewenstein A, Perlman I. Safety evaluation of repeated intravitreal injections of bevacixumab and ranibizumab in rabbit eyes. Retina. 2010;30(4):671-81.

2. Zhang M, Zhang J, Yan M, Li H, Yang C, Yu D. Recombinant anti-vascular endothelial growth factor fusion protein efficiently suppresses choridal neovascularization in monkeys. Mol Vis. 2008;14:37-49.

3. Lichtlen P, Lam TT, Nork TM, et al. Relative contribution of VEGF and TNF-alpha in the cynomolgus laser-induced CNV model: comparing the efficacy of bevacizumab, adalimumab, and ESBA105. Invest Ophthalmo Vis Sci. 2010;51(9):4738-45.

4. Olvera-Montaño O, Baiza-Durán L, Quintana-Hau JD, et al. Comparing the efficacy of an anti-human VEGF-A neutralizing antibody versus Bevacizumab on a laser-induced choroidal neovascularization (CNV) rhesus monkey model. Drug Des Dev Ther. 2019;13:3813-21.

5. Carrillo-Alarcón LC, López-López E, Hernández-Aguilar C, Martínez-Cervantes JA. Prevalencia de retinopatía diabética en pacientes con diabetes mellitus tipo 2 en Hidalgo, México. Rev Mex Oftalmol. 2011;85(3):142-7.

6. Prado-Serrano A, Guido-Jiménez MA, Camas-Benítez JT. Prevalencia de retinopatía diabética en población mexicana. Rev Mex Oftalmol. 2009:83(5):261-6

7. van Asten F, Michels CTJ, Hoyng CB, et al. The cost-effectiveness of bevacizumab, ranibizumab and aflibercept for the treatment of age-related macular degeneration-A cort-effectiveness analysis from a societal perspective. PLoS ONE. 2018;13(5):e0197670.

8. Zhang Y, Han Q, Ru Y, Bo Q, Wei RH. Anti-VEGF treatment for myopic choroid neovascularization: from molecular characterization to update on clinical application. Drug Des Dev Ther. 2015;9:314-21.

9. CATT Research Group, Martin DF, Martin DF, Maguire MG, et al. Ranibizumab and bevacizumab for neovascular age-related macular degeneration. N Engl J Med. 2011;364(20):1897-908

10. Gehlbach PL, Purple RL. An electrical artifact associated with ERG-jet gold foil electrode. Invest Ophthalmol Vis Sci. 1993;34(8):2596-9.

11. Feiner L, Barr EE, Shui YB, Holekamp NM, Brantely MA Jr. Safety of intravitreal injection of bevacixumab in rabbit eyes. Retina. 2006;26(8):882-8.

12. Manzano RP, Peyman GA, Khan P, Kivilcim M. Testing intravitreal toxicity of bevacizumab (Avastin). Retina. 2006;26(3):257-61.
13. Zayit-Soudry S, Zemel E, Barak A, Perlman I, Loewenstein A. Safety of intravitreal bevacizumab in the developing rabbit retina. Retina. 2011:31(9):1885-95.

14. Bakri SJ, Cameron JD, McCannel CA, Pulido JS, Marler RJ. Absence of histologic retinal toxicity of intravitreal bevacizumab in a rabbit model. Am J Ophthalmol. 2006;142(1):162-4.

15. Shahar J, Avery RL, Heilweil G, et al. Electrophysiologic and retinal penetration studies following intravitreal injection of bevacizumab (Avastin). Retina. 2006:26(3):262-9.

16. Sancho-Tello M, Johnsen-Soriano S, Muriach M, et al. Transient bevacizumab (avastin)-induced alterations in rat eyes. Ophthalmic Res. 2009:41(1):28-35.

17. Jung JH, Lee JE, Choi HY. Safety of bevacizumab on extraocular muscle in a rabbit model. Korean J Ophthalmol. 2012;26(4):290-6.

18. Severns ML, Johnson MA. The care and fiffing of Naka-Rushton functions to electroretinographic intensity-response data. Doc Ophthalmol. 1993;85(2):135-50.

19. Ramon D, Shahar J, Massarweh A, et al. Retinal toxicity of intravitreal injection of Ziv-Aflibercept in albino rabbits. TransI Vis Sci Technol. 2018;7(6):23.

20. Ioshimoto GL, Camargo AA, Liber AMP, et al. Comaprison between albino and pigmented rabbit ERGs. Doc Ophtahlmol. 2018;136(2):113-23.

21. AVMA (American Veterinary Medical Association), Panel on Euthanasia. AVMA Guidelines for Euthanasia of Animals. 2013th ed. Shaumburg: AVMA: 2013.

22. Luebke J, Anton A, Bach M. Test-retest reliability of scotopic full-field electroretinograms in rabbits. Doc Ophthalmol. 2017;134(3):157-65.

23. Falavarjani KG, Nguyen QD. Adverse events and complications associated with intravitreal injection of anti-VEGF agents: a review of literature. Eye. 2013;27(7):787-94.

24. Agrawal S, Joshi M, Christoforidis JB. Vitreous inflammation associated with intravitreal anti-VEGF pharmacotherapy. Mediat Inflamm. 2013;2013:943409.

25. Sinapis Cl, Routsias JG, Sinapis Al, et al. Pharmacokinetics of intravitreal bevacizumab (Avastin ${ }^{\circledR}$ ) in rabbits. Clin Ophthalmol. 2011:5:697-704.

26. Charan J, Kantharia ND. How to calculate sample size in animal studies? J Pharmacol Pharmacother. 2013;4(4):303-6.

27. Festing MF. Reduction of animal use experimental and quality of experiments. Lab Anim. 1994;28(3):212-21.

\section{Publisher's Note}

Springer Nature remains neutral with regard to jurisdictional claims in published maps and institutional affiliations.
Ready to submit your research? Choose BMC and benefit from:

- fast, convenient online submission

- thorough peer review by experienced researchers in your field

- rapid publication on acceptance

- support for research data, including large and complex data types

- gold Open Access which fosters wider collaboration and increased citations

- maximum visibility for your research: over 100M website views per year

At BMC, research is always in progress.

Learn more biomedcentral.com/submissions 